\title{
STUDIES ON PAIN. A NEW METHOD FOR MEASURING PAIN THRESHOLD: OBSERVATIONS ON SPATIAL SUMMATION OF PAIN
}

\author{
By J. D. HARDY, H. G. WOLFF, AND H. GOODELL \\ (From the Russell Sage Institute of Pathology, in affiliation with the New York Hospital and \\ Departments of Medicine and Psychiatry, Cornell University Medical College, New York)
}

(Received for publication April 18, 1940)

The purpose of these studies has been to present a new method for measuring pain thresholds, together with experimental observations on the physiology of pain and on the effect of various chemical agents upon pain thresholds.

Methods for estimating the intensity of the stimulus required to evoke a painful sensation in the skin may be classified under the headings: mechanical, chemical, electrical, and thermal. The mechanical devices as used by von Frey (1) and by Eddy (2), involving production of pain by pressure, empirically correlated the amount of pressure and the pain threshold. The deformation and internal stresses in the tissues responsible for the sensation were not investigated, and it may not be assumed that there is a simple proportionality between the pressure and the intensity of the sensory stimulus. The chemical methods of irritating the skin have not been thoroughly explored.

The thermal methods of producing pain are among the oldest and were introduced as a method of study by Goldscheider (3) in 1884. These methods, involving application of hot objects to the skin or immersion of a member in hot water, have added little of a quantitative nature to the study of pain sense. The only method of study for which the relation of the stimulus to its physiologic and sensory effects has been investigated, is the electrical method of stimulating with Faradic current, introduced by Helmholtz (4) and studied carefully by Martin (5). This method has been widely used, largely in the study of the action of analgesics by Martin and his co-workers and by Macht and his associates (6). Recently, Hauck and Neuert ( 7 ) have used high frequency currents in the study of pain thresholds.

Valuable work has been done with the above methods but none of them combines the flexibility and precision necessary for some investigations. The use of thermal radiation for the study of pain has many advantages, the most important of which are:

1. The necessary apparatus is simple and easily constructed.

2. The intensity of the stimulating agent can be precisely measured.

3. The sensory threshold to pain as a result of this stimulus is a sharply defined experience so that thresholds may be determined with accuracy higher than that of other methods.

4. The method is flexible so that the time of exposure to the stimulus, the state of the skin, etc., can be varied at will.

5. The stimulus can be used for large and small areas of skin even though the surface be irregular.

6. The stimulus can be repeated in rapid succession without injury to the skin surface tested.

Radiation was first used to stimulate skin sensation by Alrutz (8) in 1897. In 1921 Sonne (9) focussed the rays of the sun onto the skin to produce pain. Neither of these authors was studying pain, although Sonne showed that the white human could stand more penetrating radiation than non-penetrating radiation. In 1934 Dallenbach (10) used radiation to produce pain in an investigation of adaptation.

The experiments of Oppel and Hardy (11) demonstrated that the radiation technique could be applied quantitatively to the study of temperature sense, and the methods devised by these authors have been adapted to the measurement of pain thresholds. The pain is produced by concentrating the radiant energy from a powerful source onto the skin. The sensation produced is sharp, a "bright pain" (12), and is to be distinguished from an ache or deep pain. Whereas our observations apply specifically to pain in the skin, it is probable that they have broader implications. 


\section{METHOD}

The apparatus for measuring the pain threshold is shown schematically in Figure 1.

The light from a 1000 watt lamp, $L$, was focussed by a condensing lens, $C$, through a fixed aperture onto the blackened forehead of the subject, $H$. The surface of the forehead to be tested was thoroughly blackened with India ink. This measure was taken to insure total absorption of the radiation, regardless of pigmentation of the skin, and to eliminate possible effects due to the penetration of the rays below the skin surface. The stimulus could thus be considered as purely thermal.

The intensity of the radiation was controlled by means of a rheostat, $R H$. Immediately in front of the lamp was mounted an automatic shutter, $P$, which was arranged to allow the radiation to pass through to the subject for exactly 3 seconds. This time interval was so short that the heating of the skin was local and effects due to conduction at the edges of the aperture could be neglected. Thus, the temperature changes in the exposed area were assured to be uniform. It was necessary that the time of stimulation be fixed precisely as the pain threshold depended upon this factor. In the present apparatus $P$ was fixed to a heavy pendulum. The shutter, $S$, was operated manually, and allowed stimulation of the subjects when desired.

The method of making the measurement of pain threshold was as follows: The subject seated himself and placed his forehead in position. The aperture was arranged so that $3.5 \mathrm{~cm} .{ }^{2}$ of blackened skin could be exposed. After a minute or so the shutter, $S$, was lowered and the radiation allowed to fall on the skin for 3 seconds. The subject reported on his sensation. If no pain was experienced, the intensity of the light was increased and after 30 to 60 seconds the test was repeated. This procedure was followed until the subject just felt pain at the end of the exposure. This threshold pain was easily recognizable even by untrained subjects. The sensation was that of heat finally "swelling" to a distinct, sharp stab of pain at the end. When this condition had been reached the radiometer, $R$, was placed in the aperture in place of the forehead of the subject and the intensity of the radiation measured in $\mathrm{gm}$. cal./sec./cm. ${ }^{2}$ This value was considered to be the minimum stimulus for pain and was shown to be proportional to any thermal changes taking place in the skin, whether the total change or rate of change of skin temperature or both be considered. The radiometer was calibrated by means of a radiation standard of the U. S. Bureau of Standards and also with an experimental black body.

The time required to make a single observation was usually less than 2 minutes. The maximum variation from the mean was in all cases less than 12 per cent, and several measurements agreeing within 2 per cent were made to establish a threshold. Among the physical factors which were found to influence the threshold were those which tended to increase the rate of heat loss from the skin. Sweating was found to cause a great decrease in the effectiveness of this type of stimulus. Also strong drafts and especially cold rooms had to be avoided. Circumstances which affected the condition of the skin, such as sunburn, calluses, or skin lesions, changed the level of the threshold. As the skin temperature had some influence on the threshold, most tests were made on the forehead. The forehead temperature is constant (34.0 \pm $0.5^{\circ} \mathrm{C}$.) over a wide range of external temperatures $\left(20-28^{\circ} \mathrm{C}\right.$. $)$, barring sweating from any cause.

\section{RESULTS}

The measurements of pain threshold on the 3 subjects over a period of a year are shown in

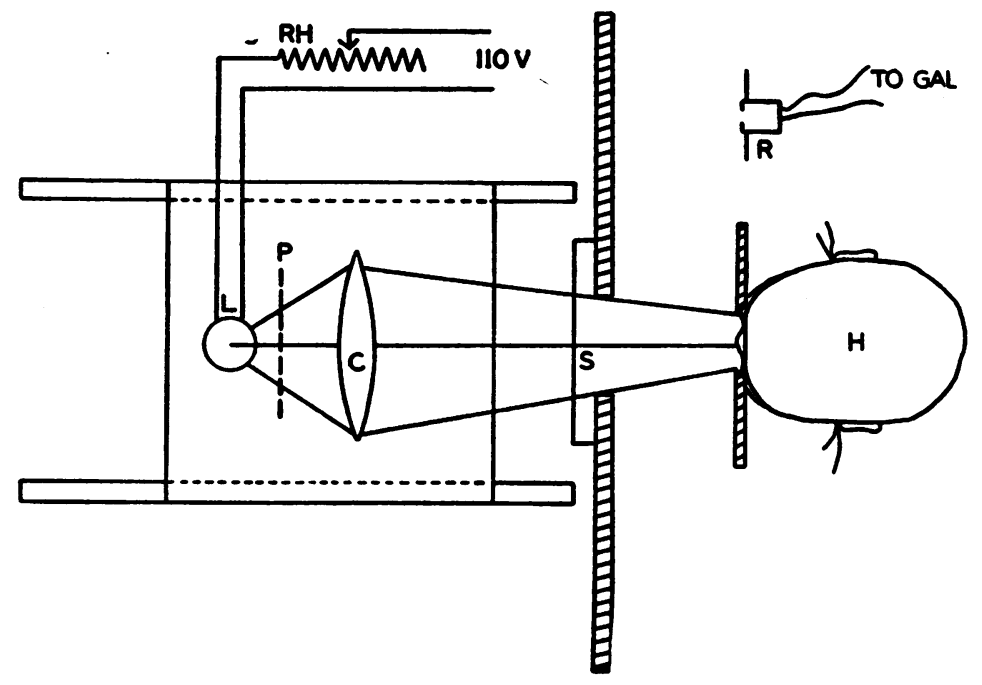

Fig. 1. Arrangement of Apparatus for Measuring Pain 


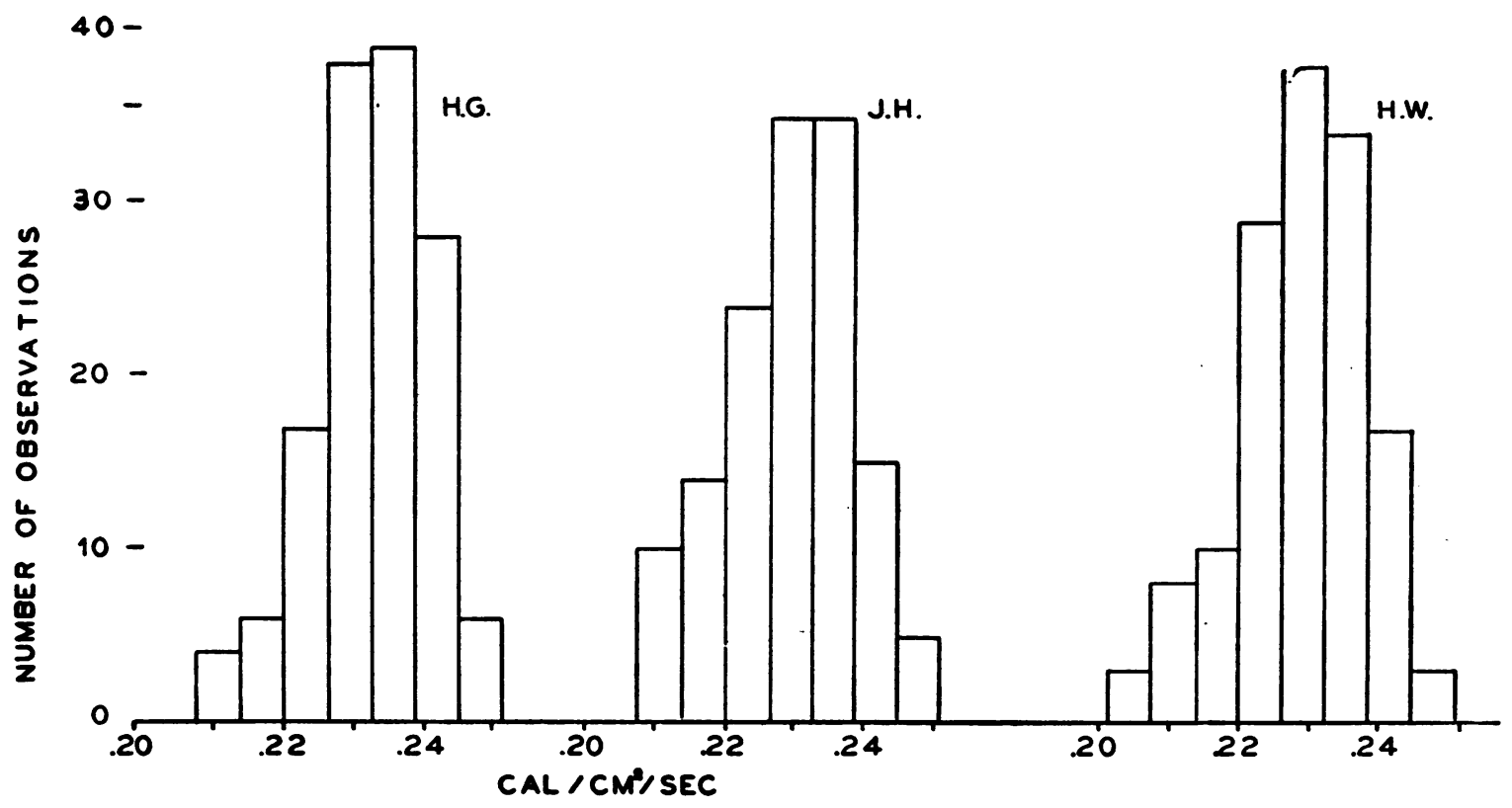

Fig. 2. Frequency Charts of Pain Threshold Measurements for 3 Subjects

Figure 2. Half the measurements on any subject were within \pm 2 per cent. Further, all 3 subjects had nearly the same thresholds, i.e., 0.229 , $0.231,0.233 \mathrm{gm}$. cal. $/ \mathrm{sec} . / \mathrm{cm}^{2}{ }^{2}$ for $\mathrm{H}$. G. W., J. D. H., and H. G., respectively. Any single measurement could be expected to be within \pm 5 per cent of this average value. Daily measurements of pain thresholds were made over a period of about a year. Before measuring pain thresholds, estimates were made by each subject concerning his or her general effectiveness as regards daily tasks and emotional state. These varied considerably from day to day, but their effect on pain threshold was in every case less than 12 per cent, and there was no constant relationship between any mood variant and the pain threshold. There was no anxiety on the part of the subjects as regards the experimental procedure and the fact that the pain threshold remained independent of emotional state should not be taken to mean that the subjects reacted to the pain in the same way every time. Martin (5), using Faradic current as stimulus, observed a diurnal variation in pain threshold, or irritability, with a low point at 10 a.m. to 11 a.m. and a high point at 4 p.m. to 5 p.m. On the other hand, Macht (6), with the same method, could demonstrate no change at all during a 26-hour experiment. Our measurements, made at various times of the day between
9 a.m. and 7 p.m., showed no significant changes with time of day.

Except for procedures directly affecting the skin and chemical agents having analgesic action, we have demonstrated few factors affecting the pain threshold. Binding the head firmly with a bandage through which a window was cut for the threshold measurement was found to increase the average threshold by about 4 to 6 per cent. This rise, though definite, shows that an intense sensation due to a stimulus which is not painful affects the pain threshold to a minor degree. Gripping a bar as tightly as possible was found to raise the threshold in one subject 7 per cent, and in another 15 per cent. As gripping the bar was slightly painful, a larger increase in threshold resulted than in the case of bandaging the head. An extremely loud and penetrating noise produced by striking a metal plate held just behind the subject's head caused a rise of 14 to 32 per cent in 2 subjects, depending upon the duration of the stimulus. Continued striking for 30 seconds produced a rise of 25 to 30 per cent. The intensity of sound was so great as to be "painful." It would be expected that other factors, such as the excitement of a contest or an accident, would have appreciable effects on the reaction to pain. This matter will be discussed in a subsequent communication. 
The nature of the sensations resulting from irradiating the skin is of interest. In 1884 Goldscheider (3) claimed to have demonstrated that the sensation of pain or burning is not mediated by the end organs of heat. In order to make certain that in these experiments we were dealing with pain and not a strong sensation of heat, the following two experiments were performed.

In the first experiment the thresholds of pain and of heat were determined on 2 subjects. Then 1.8 grams of acetylsalicylic acid were given by mouth. The changes in thresholds for both heat and pain were followed for 4 hours (Figure 3 ). The pain threshold was raised 35 per cent, whereas the heat threshold was actually lowered 55 per cent. This differential effect of the drug clearly separates the two sensations. In the second experiment it was shown that the peripheral structures mediating pain and heat sensations are entirely separate. Pain thresholds were measured on the back of the left hand and on the forehead. A sphygmomanometer cuff was then wound around the left arm above the elbow and inflated to a pressure of $200 \mathrm{~mm}$. of $\mathrm{Hg}$. The pain thresholds on hand and forehead were followed for 35 minutes, the pressure in the cuff released, and thresholds followed until normal values were again obtained. Estimates of the amount of pain resulting from the manometer cuff were made, and the " $6+$ pain" just before release of the pressure represents an almost intolerable state. It was repeatedly demonstrated that after 35 minutes of ischemia, sensation in the hand had almost disappeared with the exception of pain. From this experiment it seems probable that pain and temperature are not served by the same peripheral apparatus.

Figure 4 demonstrates the course of the above experiment. The solid line represents the change in threshold of the ischemic hand, and the dashed line the change in threshold of the forehead. Since the pain threshold in the ischemic arm was elevated to the same degree as that in the forehead, one may conclude that the observed effect was due to pain resulting from the ischemia rather than from the ischemia itself. It has been men-

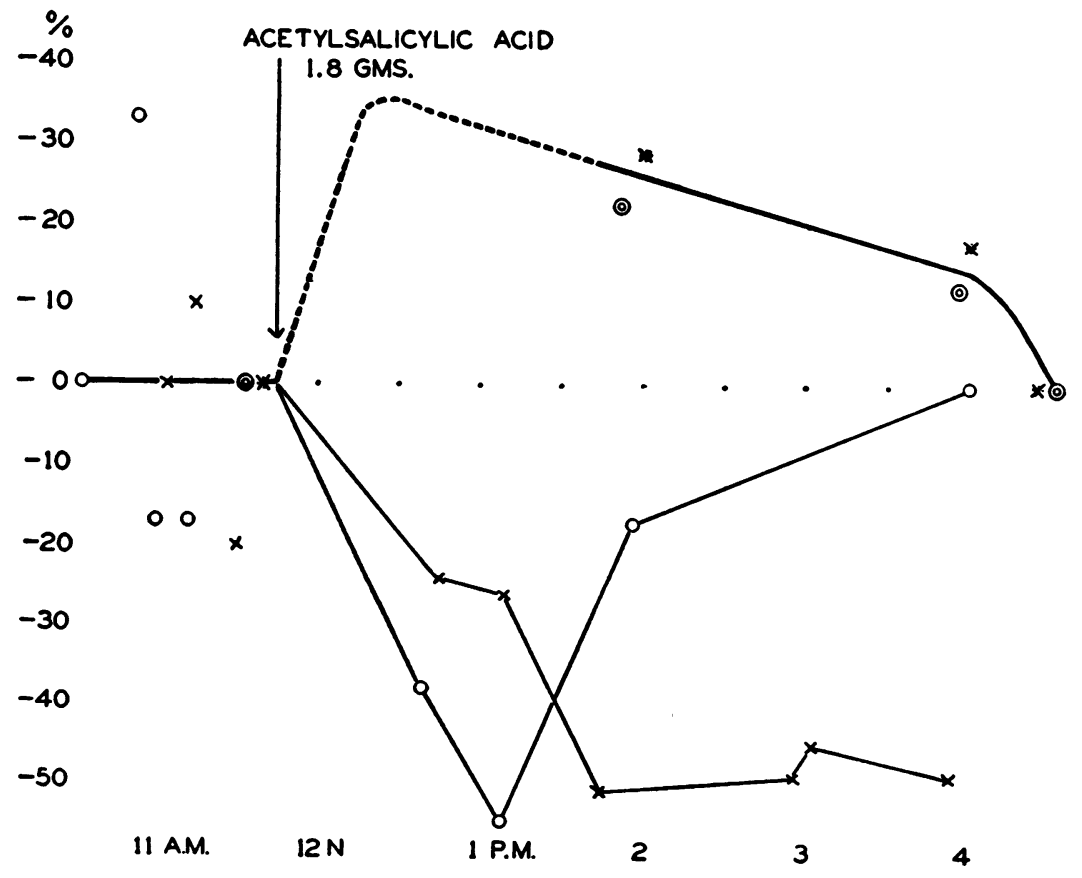

Fig. 3. Effect of Acetylsalicylic Acid Upon the Thresholds to Heat and to Pain

Double circles and dotted crosses $=$ pain ; single circles and crosses $=$ heat. (Dashed portion taken from different experiment with same amount of agent.) 

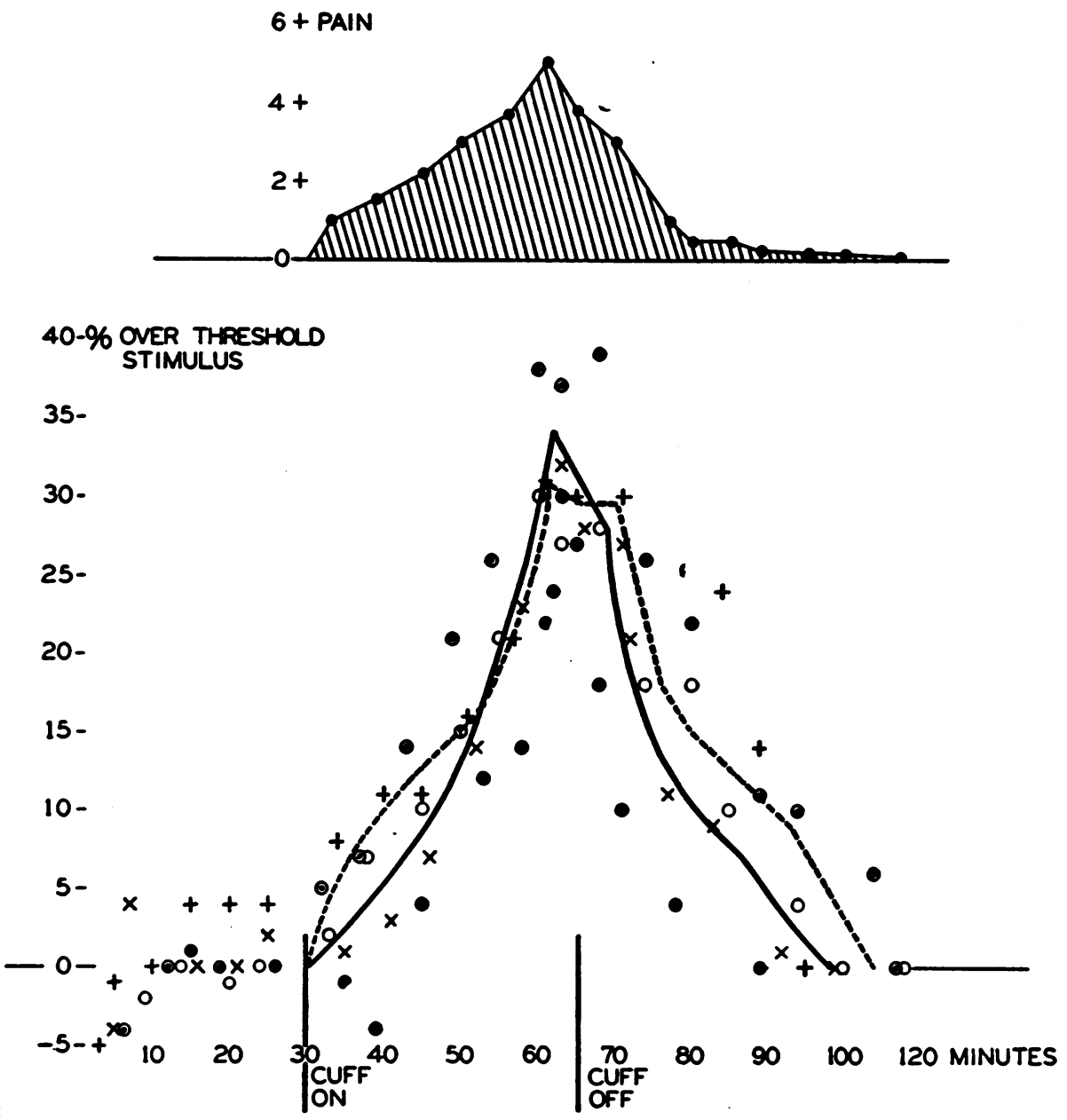

Fig. 4. The Effect of Arresting the Blood Flow to the Left Arm Upon the Pain Threshold in the Left Hand (Dashed Line) and on Forehrad (Solid Line)

Upper shaded area represents the subjective estimates of the pain caused by the ischemia in the arm.

tioned above that pain induced by methods other than those involving ischemia also raises the pain threshold.

Furthermore, the above experiment indicates that pain occurring in one part of the body causes a rise in the pain threshold in the rest of the body. It also appears that the pain threshold rose with the increase in the intensity of pain from the cuff. The maximum height of this effect was between 30 and 40 per cent above the normal threshold. Also, as will be discussed in a later communication, various chemical agents raise the pain threshold (13).

Hardy and Oppel (14) demonstrated almost perfect spatial summation for heat and cold sen- sations on the forehead. That is, as the area exposed to the radiation was increased, the strength of stimulus necessary to evoke sensation decreased almost in proportion. Application of this method to pain was made in an attempt to demonstrate spatial summation. The experiments on pain were carried out in a similar manner to those on temperature sense, except that smaller areas were stimulated. However, series of areas were used, with a ratio of extreme sizes of $400: 1$. The data for 2 subjects are shown in Table I.

From the smallest to the largest areas there was a slight decrease in the intensity of stimulus necessary to evoke pain. This may be due to slight spatial summation, or what is more likely, to the 
TABLE I

Intensity of radiation required to evoke pain, with three seconds' exposure, for various sized areas of skin on the forehead

\begin{tabular}{|c|c|c|c|}
\hline Area & Subject G & Subject H & Average \\
\hline $\begin{array}{l}c m .2^{2} \\
0.07\end{array}$ & $\begin{array}{c}\text { gm.cal. } / \mathrm{sec} . / \mathrm{cm} .2 \\
0.287 \\
0.314\end{array}$ & $\begin{array}{c}\text { gm.cal. } / \mathrm{sec} . / \mathrm{cm} . .^{2} \\
0.247 \\
0.265\end{array}$ & $\begin{array}{c}\text { gm.cal. } / \mathrm{sec} . / \mathrm{cm} .2 \\
0.277\end{array}$ \\
\hline 0.13 & $\begin{array}{l}0.262 \\
0.264 \\
0.269\end{array}$ & $\begin{array}{l}0.245 \\
0.257 \\
0.252\end{array}$ & 0.258 \\
\hline 0.19 & $\begin{array}{l}0.259 \\
0.254 \\
0.265\end{array}$ & $\begin{array}{l}0.257 \\
0.255 \\
0.255\end{array}$ & 0.258 \\
\hline 0.95 & 0.258 & 0.228 & 0.243 \\
\hline 3.46 & 0.249 & 0.228 & 0.236 \\
\hline 7.10 & 0.240 & 0.242 & 0.242 \\
\hline 10.00 & 0.240 & 0.225 & 0.233 \\
\hline 28.30 & 0.256 & $\begin{array}{l}0.241 \\
0.241\end{array}$ & 0.245 \\
\hline
\end{tabular}

subject's underestimation of the pain threshold as a result of the strong sensation of heat which precedes the pain with the large areas. For the largest area, the heat stimulus was more than 400 times the threshold value; for the smallest area the sensation of heat was often not present at all. Thus, when large areas of the forehead were exposed to the radiation, the thermal sensation was so strong that experience warned that pain was imminent, and with the smallest areas in which no heat sense was present pain was felt only as a prick. It is necessary that the time of exposure be short ( 3 seconds or less) for this experiment in order to obtain the same heating rate for all sized areas. Figure 5 shows a comparison of the area stimulated and intensity of stimulus required to evoke the sensations of heat and pain. The comparison is made on the basis of the rate of rise of skin temperature. Other relations, such as total change in skin temperature and the rate of energy absorbed, are proportional to the stimulus measured in these terms. It is evident that there is little, if any, spatial summation of pain sensation of the type found with heat sense or cold sense.

The pain curve (Figure 5) shows the relationship between intensity of stimulus and area which must exist if there be no spatial summation. The existence of this relationship, however, does not prove that there is no spatial summation for pain. That is, even though enlarging the exposed area did not reduce the intensity of stimulus necessary to evoke pain, spatial summation for stronger stimuli was not excluded. Thus, $0.230 \mathrm{gm}$. cal./ $\mathrm{sec} . / \mathrm{cm} .^{2}$ may represent both the threshold of excitation for the end organs and the sensory threshold of pain, and a lower stimulus would not be expected to evoke a pain regardless of the amount of spatial summation present. This would correspond to the finding of Hardy and Oppel (14) for temperature sense with large areas. (They observed that when $200 \mathrm{~cm}^{2}$ of surface had been exposed they could not further decrease the threshold stimulus no matter how much larger area was irradiated.) There is subjectively a " bigger" pain with $28 \mathrm{~cm}^{2}$ than with $0.07 \mathrm{~cm}^{2}$ of exposed surface, although the intensity of pain did not seem to be different.

In order to test whether or not spatial summation exists with supraminimal stimuli and to apply threshold measurements for such a purpose, it was necessary to administer an analgesic agent (morphine) whose action can be assumed to be central rather than peripheral. If under such circumstances there were spatial summation for these supraminimal stimuli, the pain threshold would be raised by the morphine to a smaller degree in a large area than in a small area. In other words, if increasing the size of the area exposed had had the same effect as increasing the intensity of the radiation, the morphine would have raised the pain threshold less for the large area.

The following experiment was performed on 2 subjects: Threshold stimuli were measured for areas $0.3 \mathrm{~cm}^{2}$ and $3.46 \mathrm{~cm}^{2}$, the latter representing more than eleven-fold increase in area. This area ratio, on the basis of the summative effects found in temperature sense, would have been ample to show spatial summation of pain if it existed. After obtaining normal thresholds, morphine was administered to the subjects and the change in threshold in these two areas was followed for 6 hours. Since morphine acts centrally, it may be assumed that pain impulses from both areas were being evoked when the stimulus was above the normal threshold and that more pain impulses were arising from the larger area than from the smaller. 


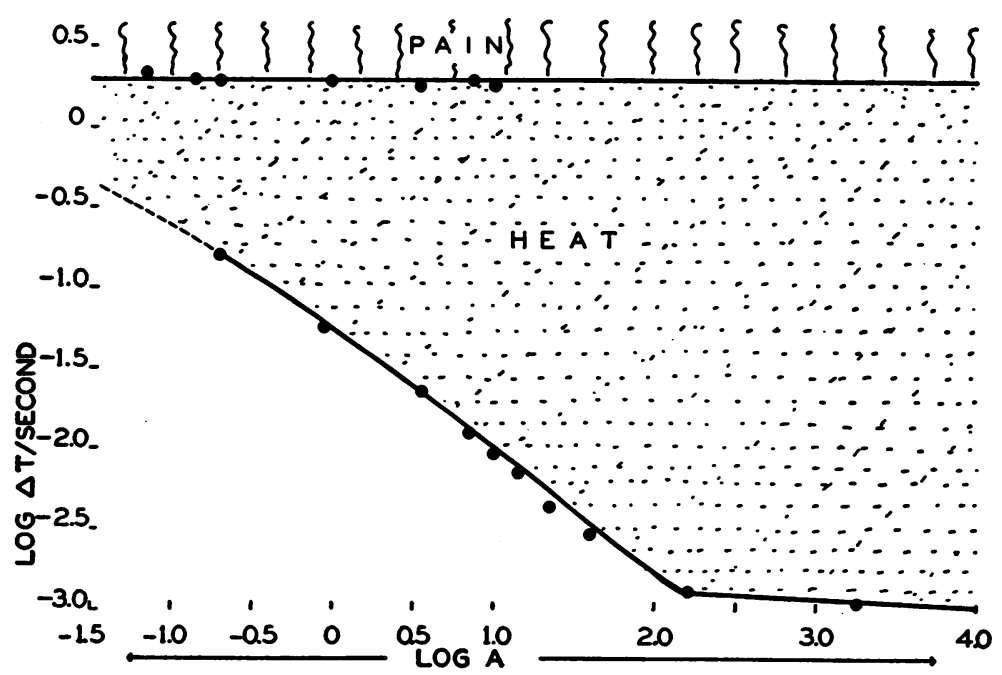

Fig. 5. Relationship Between Log Intensity of Threshold Stimulus (Rate of Change of Skin Temperature in Degrees per Second) and the Log Area Stimulated

Upper curve $=$ pain; lower curve $=$ heat.

The results of the experiment are shown in for pain does not exist. In any case, it has not Figure 6, and it is seen that the morphine caused been possible to demonstrate spatial summation the same rise in threshold to pain in the two areas. for pain.

Thus, one must conclude either that morphine acts Lack of summation indicates that the central to prevent spatial summation or that summation representation for superficial pain is different

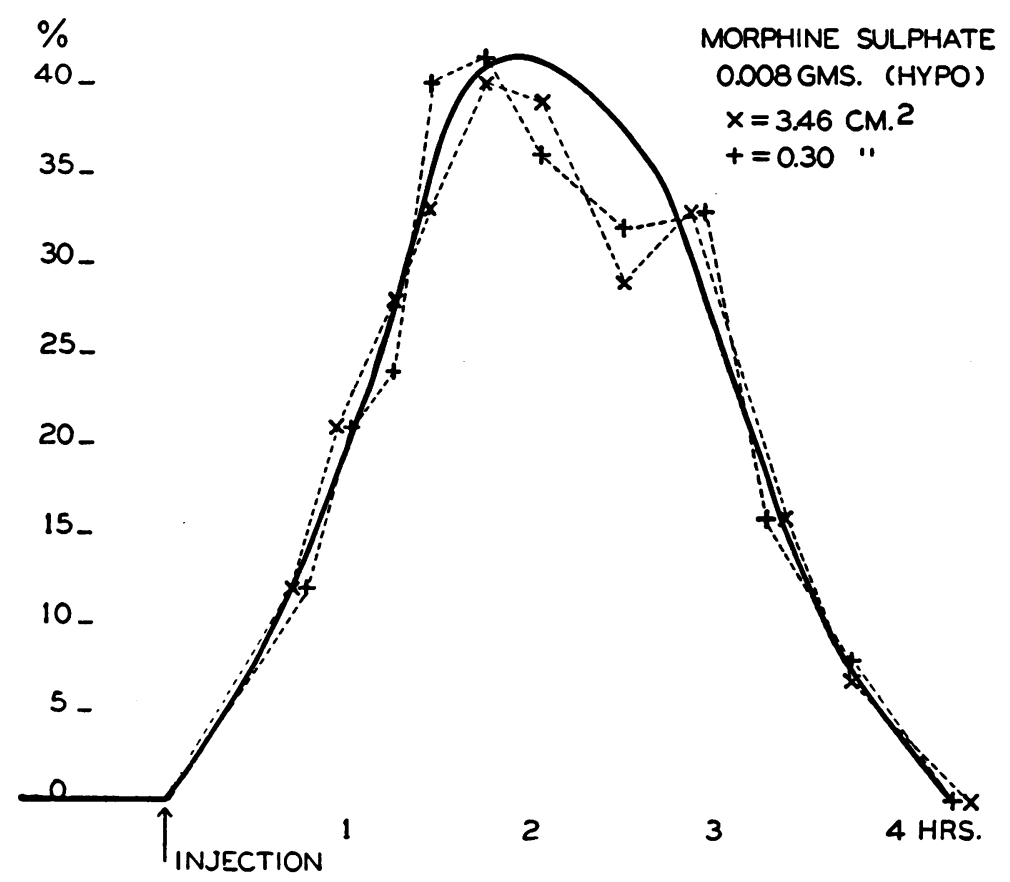

Fig. 6. Effect of Morphine Upon the Threshold Stimuli from Large and Small Areas 
from that of temperature and touch. Pain is increased in intensity only by increasing the intensity of the stimulus and not by association of larger numbers of impulses from various sources. Therefore, the evidence from both the peripheral and central components of the pain apparatus suggests that functionally pain is distinct from other sensations. These demonstrated differences imply a system of discrete neural units for pain sense. It is useful to consider pain as a unique esthetic experience with its own physiological properties and neural mechanisms.

The range of stimuli from the excitation threshold of most sensations up to the pain threshold is great. With sight the ratio is greater than $10^{6}: 1$, with temperature $10^{3}: 1$, and other senses have ratios lying in this range. The body, because of spatial summation, is therefore extremely sensitive to stimuli of these types. The ratio between the stimulus evoking threshold pain and that causing tissue destruction is about 2 to 1 . Thus, $0.230 \mathrm{gm}$. cal./sec./cm. ${ }^{2}$ will evoke a threshold pain in 3 seconds; in the same time $0.460 \mathrm{gm}$. cal. $/ \mathrm{sec} . / \mathrm{cm}^{2}{ }^{2}$ will invariably produce blistering and cause an extremely intense pain. Obviously, a similarly intense pain would result from a relatively mild stimulus over a large area were there spatial summation for pain, mitigating against the organism. Adequate provision has been made through pain to warn the organism of the approach of tissue damage without effecting a sensitiveness which would make life unbearable. It is nevertheless true that the individual is aware of multiple pains and that discomfort is increased according to the size of body area involved. For many obvious reasons a sunburn over the entire body surface will cause more distress than that over a $1 \mathrm{~cm}^{2}$ area, even though the intensity of the pain in each case be the same. In this sense the distress of the organism must be considered as a function of both the intensity of the stimulus and the size of the area over which it is effective.

\section{SUMMARY AND CONCLUSIONS}

1. A quantitative method for measuring pain thresholds in the skin by thermal radiation has been described. The method has the general advantage of measuring a physical quantity which is directly proportional to the changes occurring in the skin. The method has the further advantages of precision, simplicity of technique, rapidity of measurement, and the fact that the stimulus is innocuous upon repeated application except at high intensities. Further, any part of the skin surface may be studied and the size of the stimulated area varied at will.

2. Pain thresholds measured in this way did not vary consistently with time of day, with the general effectiveness, or the emotional state of the 3 subjects.

3. Individual threshold measurements for 3 subjects were $0.229,0.231$, and $0.233 \mathrm{gm}$. cal./ sec. $/ \mathrm{cm} .^{2}$ and all measurements were found to be within \pm 12 per cent of their respective average values. The standard deviation for a single measurement was calculated to be \pm 2 per cent.

4. Intense pain in any part of the body raised the pain threshold in the skin in other parts as much as 35 per cent.

5. The senses of pain and heat, which were always stimulated together, were shown to be separate sensations through the action of acetylsalicylic acid. This drug lowered the heat threshold and raised the pain threshold.

6. The peripheral structures responsible tor pain sense were distinguished from those of temperature and touch by demonstrating that occluding the blood for 25 minutes did not directly affect the pain threshold in the ischemic hand, whereas other sensations could hardly be elicited.

7. Pain sense was found to have no spatial summation in the sense that the pain threshold for many end organs was no lower than that for a few. This was observed to be the case for minimal stimuli and for supraminimal stimuli after morphine administration.

8. The intensity of radiation which produced blistering in 3 seconds was observed to be twice that necessary for the bare perception of pain.

\section{BIBLIOGRAPHY}

1. von Frey, M., Untersuchungen über die Sinnesfunctionen der Menschlichenhaut. Erste Abhandlung: Druckempfindung und Schmerz. (Neunter Abschnitt. Die Messung von Schmerzschwellen) Abhandl. d. Math. Phys. Cl. d. K. Sächs. Gesellsch. d. Wissensch., 1897, 23, 169. 
2. Eddy, N. B., Studies of morphine, codeine and their derivatives; general methods. J. Pharmacol. and Exper. Therap., 1932, 45, 339.

3. Goldscheider, A., Temperatursinn des Menschen. Handbuch der Normalen und Pathologischen Physiologie, Springer, Berlin, 1926, vol. 11, 131.

4. Helmholtz, H., Ueber die Dauer und den Verlauf der durch Strömesschwankungen inducirten elektrischen Ströme. Poggendorf's Annalen der Physik und Chemie, 1851, 83, 505.

5. Martin, E. G., A quantitative study of faradic stimulation. II. The calibration of the inductorium for break shocks. Amer. J. Physiol., 1908, 22, 116.

6. Macht, D. I., Herman, N. B., and Levy, C. S., A quantitative study of the analgesia produced by opium alkaloids, individually and in combination with each other in normal man. J. Pharmacol. and Exper. Therap., 1916, 8, 1.

7. Hauck, A., and Neuert, H., Untersuchungen über die Hautsensibilität; Die Schmerzschwellen bei elektrischer Reizung des sensiblen Nerven. Arch. f. d. ges. Physiol., 1937, 238, 574.
8. Alrutz, S., Studien auf dem Gebiete der Temperatursinne. I. $\mathrm{Zu}$ den Kälte und Wärmepunkten. Skandinav. Arch. f. Physiol., 1897, 7, 321.

9. Sonne, $\mathrm{C}$., The mode of action of the universal light bath: visible and invisible heat rays. Acta Med. Scandinav., 1921, 54, 350.

10. Dallenbach, K. M., Adaptation to the pain of radiant heat. Am. J. Psychol., 1934, 46, 229.

11. Oppel, T. W., and Hardy, J. D., Studies in temperature sensation. I. A comparison of the sensation produced by infra-red and visible radiation. $\mathrm{J}$. Clin. Invest., 1937, 16, 517.

12. Lewis, $T$., Suggestions relating to study of somatic pain. Brit. Med. J., 1938, 1, 321.

13. Wolff, H. G., Hardy, J. D., and Goodell, H., Studies on pain. Measurement of the effect of morphine, codeine and other opiates on the pain threshold and an analysis of their relation to the pain experience. J. Clin. Invest., 1940, 19, 659.

14. Hardy, J. D., and Oppel, T. W., Studies in temperature sensation. III. The sensitivity of the body to heat and the spatial summation of end organ responses. J. Clin. Invest., 1937, 16, 533. 